\title{
Study on Dynamic Behavior Law and Microseismic Monitoring in Stoping Process of Roadway with High Gas and Wide Coal Pillar
}

\author{
Baobin Gao $\mathbb{D}^{1,2,3,4}$ Chuangnan Ren $\mathbb{D}^{1,2}$ Qun Dong, ${ }^{1,2}$ and Liwei Chen ${ }^{1,2}$ \\ ${ }^{1}$ State Collaborative Innovation Center of Coal Work Safety and Clean-efficiency Utilization, Jiaozuo, Henan 454000, China \\ ${ }^{2}$ State Key Laboratory Cultivation Base for Gas Geology and Gas Control, Henan Polytechnic University, Jiaozuo 454000, \\ Henan, China \\ ${ }^{3}$ Key Laboratory of Resources, Environment and Disaster Monitoring of Shanxi Province, Taiyuan 030000, Shanxi, China \\ ${ }^{4}$ Henan Key Laboratory of Underground Engineering and Disaster Prevention (Henan Polytechnic University), Jiaozuo 454000, \\ Henan, China
}

Correspondence should be addressed to Chuangnan Ren; chuangnanrcn@163.com

Received 9 May 2021; Accepted 11 June 2021; Published 25 June 2021

Academic Editor: Junfei Zhang

Copyright (c) 2021 Baobin Gao et al. This is an open access article distributed under the Creative Commons Attribution License, which permits unrestricted use, distribution, and reproduction in any medium, provided the original work is properly cited.

In order to study the dynamic characteristics and microseismic distribution in the mining process of roadway with high gas and wide coal pillar, combined with the two dynamic events of N2105 working face in Yuwu Coal Industry, theoretical analysis and field measurement research were carried out. According to the theory of structural mechanics and geomechanics, the causes of dynamic appearance are analyzed. Combined with the specific situation, the influence of mining depth, coal pillar width, gas pressure, and content on the dynamic performance is analyzed. Stress monitoring and microseismic monitoring are carried out on one side of coal seam. The results show that, with the increase of the mining distance, the backside roof of the goaf is prone to unbalanced fracture due to the lack of lateral stress, and the impact pressure generated is used for the reserved protective coal pillar behind the goaf, causing the floor heave of coal seam. The combined stress generated by the anticlinal structure below the working face interacts with the abutment pressure of the working face to produce superposition effect, which promotes the occurrence of dynamic appearance. The critical depth of rock burst in Yuwu Coal Industry is about $600 \mathrm{~m}$. The increase of coal elastic energy caused by roof subsidence is more uniform with the increase of coal pillar width. The decrease of gas pressure in coal seam promotes the rock burst disaster. The vertical stress of coal seam at one side of the working face shows different evolution characteristics along the trend and strike. The vertical stress of coal seam in the lateral range of $53 \mathrm{~m}$ is adjusted to different degrees and tends to be stable until $300 \mathrm{~m}$ behind the working face. The active microseismic area in the middle of the working face was located $50 \mathrm{~m}$ in front of the working face, and the microseismic activity continued to $30-50 \mathrm{~m}$ behind the working face. The active microseismic area at the side of the roadway was located $30 \mathrm{~m}$ in front of the working face, and the microseismic activity continued to $100-180 \mathrm{~m}$ behind the working face. The inflection point, where the stress in the elastic area of coal pillar increases sharply, corresponds to the active microseismic area, which indicates that the dynamic characteristics in the mining process of roadway with high gas and wide coal pillar are related to the distribution law of microseismic. This study has a certain guiding significance for optimizing the width of reserved coal pillar, monitoring the coal seam stress/microseismic, and understanding the dynamic disaster of coal and rock under complex conditions.

\section{Introduction}

In recent years, with the increase of coal mining depth, most coal mines have entered the deep mining stage. Deep mining faces complex conditions such as "high stress, high gas, high ground temperature, and strong mining disturbance," which lead to the coexistence, compound and associated characteristics of rock burst, coal and gas outburst, and other dynamic disasters in deep mine, and the characteristics of multifactor coupling of dynamic disaster risk factors [1-5]. Compared with the single dynamic disaster, the threshold of the occurrence of composite dynamic disaster may be lower, 
and the occurrence intensity of disaster may be greater and more violent [6].

Since the coal mine entered deep mining, the dynamic disaster research carried out by relevant scholars has changed from single to compound dynamic disaster [7]. The composite dynamic disaster proposed dates back to the 80s, and the Soviet scholars take the lead in putting forward the impact ground pressure and coal and gas outburst together as the two disasters phenomena. After that, the impact ground pressure and coal and gas outburst are triggered, and they influence each other's point of view, and the study of the influence degree between the two began to appear [8-10]. In China, since the concept of composite dynamic disasters was proposed in the 1990s, relevant studies have developed rapidly, mainly focusing on disaster accident statistics, disaster-causing mechanism, and disaster detection and prevention and control technologies [11-15]. According to the statistics of dynamic disaster accidents during 1994-2011, after mine shocks occurred in Liaoning, Gansu, Henan, Shandong, and other provinces, abnormal gas gushing occurred, and rock burst participated in coal and gas outburst and other composite dynamic disasters [16]. Under the guidance of such incidents and scholars, first of all, from the perspective of the mechanism and to cause inoculation conditions, from the angle of mechanics analysis, simulation and deduction composite dynamic disaster was analyzed, and the preliminary shock pressure is established, as well as the unification of the outstanding phenomenon of instability theory, the formation of the "shock pressure just ignored or no gas prominent" [17]. With the deepening of theoretical research on the internal mechanism and disaster mode of composite dynamic disasters, at the same time, relevant coupling experimental research, monitoring and early warning mode and risk prevention and control technology are also constantly enriched and developed [18-21].

To sum up, the theoretical analysis, experimental study, monitoring model and prevention, and control technology of coal and rock composite dynamic disasters have been studied indepth at present. Through a large number of literature reviews, it is found that even though a certain system has been formed in the related researches of composite dynamic disasters, the current researches on rock burst in deep coal seams are still on the theoretical basis of ignoring the participation of gas, and there is a lack of indepth understanding on the research of coal burst liability under the action of gas [22]. Moreover, there are relatively few studies on the precursor monitoring and field measurement of composite dynamic disasters, and extremely few cases are also aimed at the front of excavation. Theoretical analysis and experimental study alone are not enough to guide the correct understanding of the occurrence process of composite dynamic disasters, and field measurement research of relevant specific cases is urgently needed. Therefore, combined with the measured data and data obtained from stress monitoring and microseismic monitoring after the occurrence of the dynamic occurrence event behind the N2105 working face and at the side of the goaf in Yuwu Coal Industry, the dynamic occurrence and microseismic distribution in the process of mining in the roadway with high gas and wide coal pillar are measured and analyzed. To explore the dynamic characteristics and microseismic distribution under the influence of special geological structure and gas action, in order to provide specific case support for the further study of coal and rock composite dynamic disasters, at the same time, it provides reliable program guidance for deep mine mining operation.

\section{Dynamic Development Process and Mechanism Analysis}

2.1. Event Description. At 15:40 on November 17, 2013, at the N2105 working face of Yuwu Coal Industry in Changzhi, Shanxi Province, a loud noise occurred. The floor of the roadway instantly bulged, with a maximum height of nearly $2 \mathrm{~m}$. Large blocks of coal were bounced from the floor, and even cracks occurred in the mudstone of the floor. The maximum gas concentration reached $1.34 \%$. The length of impact roadway was about $100 \mathrm{~m}$. Compared with other areas, the side roadway of coal pillar obviously shifted outward of about $400 \mathrm{~mm}$. At 22:40 on January 23, 2014, dynamic phenomenon occurred again in this roadway, and the damage scope was about $100 \mathrm{~m}$. The positions of the two dynamic manifestations are shown in Figure 1.

In the first floor heave, the belt is mined $635 \mathrm{~m}$ along the chute, and the return air is mined $631 \mathrm{~m}$ along the chute. The range of the floor heave is within the range of the air inlet chute 1800-2000 m, and the distance of the floor heave from the mining face is about $95 \mathrm{~m}$. In the second floor heave, the mining of rubber belt along the chute is $862.3 \mathrm{~m}$, and the recovery of air return is $856.2 \mathrm{~m}$. The range of floor heave is within the range of air inlet chute $1700 \mathrm{~m}-1800 \mathrm{~m}$, and the floor heave is about $222.5 \mathrm{~m}$ away from the stop-mining line of the working face. During the interval between two floor heaves, the working face rubber belt moves forward $227.3 \mathrm{~m}$ along the grooves, and the return air moves forward $225.2 \mathrm{~m}$ along the grooves. The coal body at the coal pillar side of the floor heave section was broken obviously, the middle of the roadway was high, and the two sides were low. A total of 8 groups of wood stacks were destroyed by the two events. The field conditions of floor heave in roadway are shown in Figure 2.

\subsection{Cause Analysis}

2.2.1. Structural Mechanical Analysis. The occurrence of dynamic behavior is closely related to the width of the reserved protective coal pillar between the roadway, which is directly related to whether the stress and energy brought by the roof pressure can be safely unloaded or transferred. N2105 working face adopts "double $\mathrm{U}^{\prime \prime}$ ventilation, with $35 \mathrm{~m}$ reserved in the middle to protect coal pillar. From the positions of the two dynamic appearances, it can be preliminarily concluded that the main force source for the impact of the air inlet passage at N2105 working face is the lateral support pressure caused by the lateral suspended roof of the goaf at N2105 working face. The support pressure acts on the floor of the coal seam without support through the 


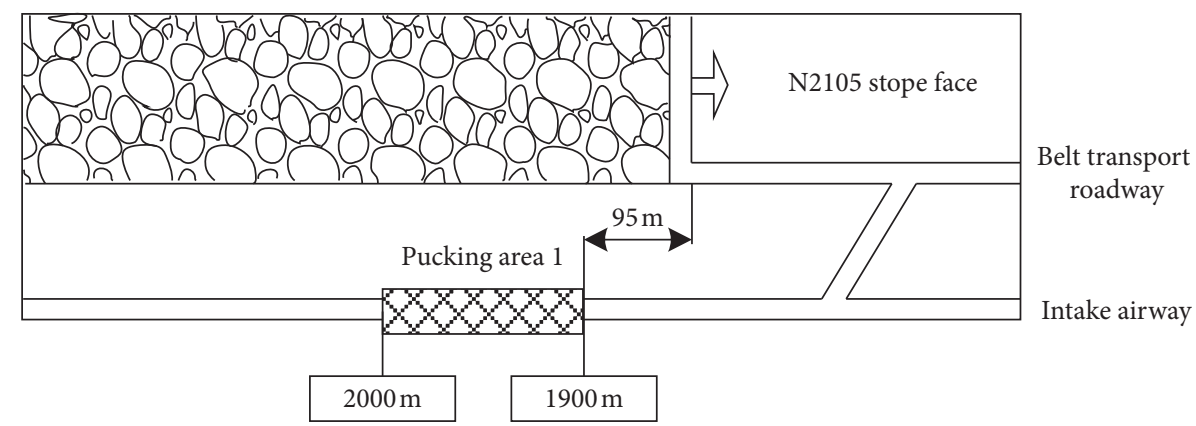

(a)

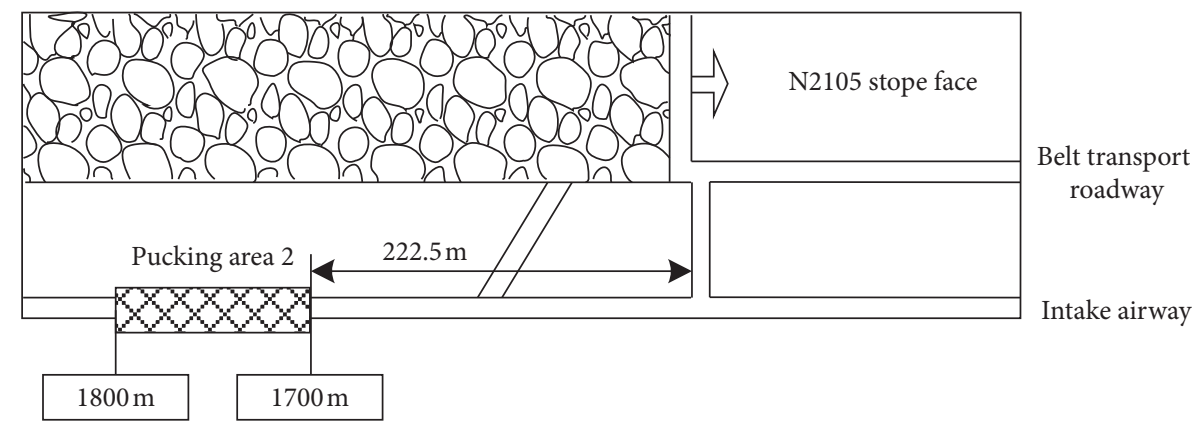

(b)

Figure 1: Diagram of two dynamic display positions.

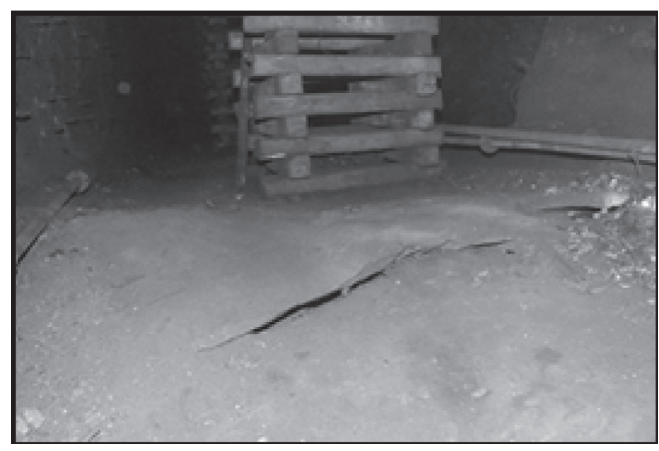

(a)

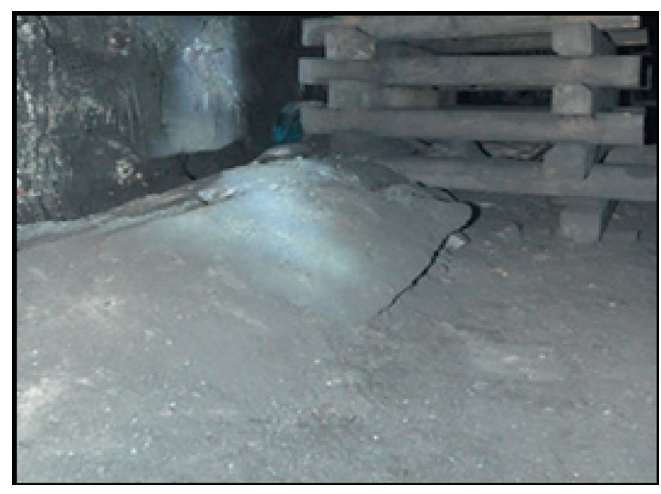

(c)

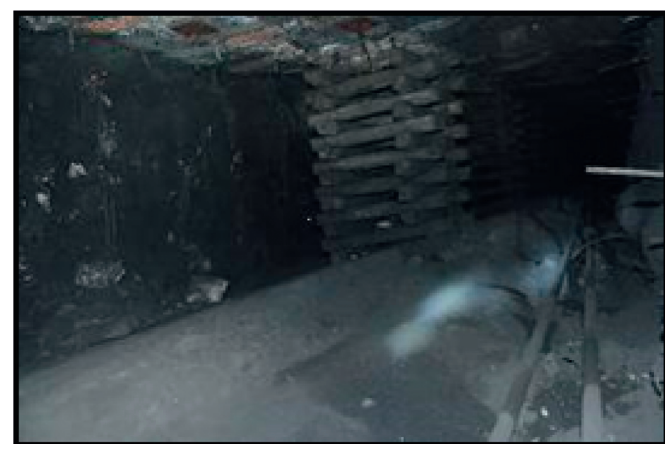

(b)

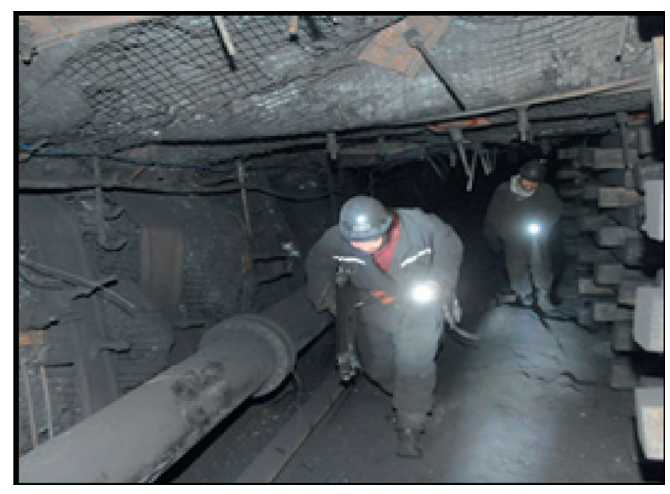

(d)

Figure 2: Situation of floor heave. 
transfer of the bearing coal pillar and is the main force source for the strong floor heave. At the same time, because the working face is in the process of mining, the coal face is affected by the back-and-forth abutment stress (as shown in Figure 3). Moreover, the No. 3 coal seam mined by Yuwu Coal Industry has weak bursting liability. By synthesizing the interaction between the three, the dynamic phenomenon is produced in the working face.

Furthermore, the reason why stress concentration occurs in front of the working face and behind the goaf is that, after the mining of the working face, rock beam structures such as "cantilever beam" and "masonry beam" are formed in the roof strata. Different structural forms directly reflect the fracture of coal seam roof and indirectly reflect the end face exposure, coal wall slicing, and the working face and end support conditions. According to relevant studies [23], the formation of rock beam structure is mainly related to the mining height of the working face and the position of the first key layer.

The cumulative mining height of coal seam in N2105 working face of Yuwu Coal Industry is $6.31 \mathrm{~m}$. The direct roof is mudstone with a thickness of $0.90-2.74 \mathrm{~m}$ and an average thickness of $1.56 \mathrm{~m}$. Above the mudstone is finegrained sandstone, which is the first key layer, with a thickness of $10.25-11.37 \mathrm{~m}$ and an average thickness of $11.00 \mathrm{~m}$. In order to accurately obtain the structural form of rock beam of N2105 working face roof, formula (1) can be used to judge:

$$
M+\left(1-K_{p}\right) \sum h_{i}>h-\sqrt{\frac{2 q l^{2}}{\sigma_{c}}}
$$

where $M$ is the mining height of the mining face, $3.2 \mathrm{~m} ; K_{p}$ is the roof expansion coefficient, which is $1.3 ; \Sigma h_{i}$ is the cumulative height of direct roof above the coal seam and below the key layer, $1.56 \mathrm{~m}$; $H$ is the key layer thickness, $11.00 \mathrm{~m}$; $l$ is the periodic fracture step of key strata, about $15 \mathrm{~m}$; $q$ is the overburden load on the key layer, about $15000 \mathrm{kN} ; \sigma_{c}$ is the compressive strength of the key layer, about $91.7 \mathrm{kN} / \mathrm{m}^{3}$.

The calculated results on both sides of the formula are $2.732>2.420$; that is, the formula is valid, judging that the roof structure of N2105 working face belongs to the structure type of "cantilever beam." When N2105 mining face distance increases to a certain extent, the roof hanging distance is big enough, with lack of rear gob roof lateral stress and sudden unbalance fault, resulting in a larger shock pressure, acting on the goaf behind the reserve protection coal pillar, through the effect of stress transfer of the protective coal pillar, the cause of coal seam floor, causing power to be revealed.

2.2.2. Geomechanical Analysis. It has been proved by practice that the fold structure area is the area of rock burst frequently during either excavation period or mining period. From the perspective of geomechanics, there are a series of small folds and faults developed in the working face of $\mathrm{N} 2105$, among which there is a main anticline structure. The axis of the anticline is distributed along the direction of "southeast to northwest," and its two sides intersect with the air inlet channel and the belt channel. Both floor heave ranges are located in the axis of the anticline. The existence of anticline structure will make the axial part and the two wings of the anticline stress concentration phenomenon, tectonic stress, and working face abutment pressure interaction produce superposition effect, which is one of the main reasons for the two dynamic appearances. The specific anticlinal structure distribution is shown in Figure 4. In the figure, red is the dynamic development area, and blue is the anticlinal axis.

In order to observe the influence of anticlinal structure on dynamic appearance more intuitively, numerical simulation was conducted for anticlinal structure, and the simulation size was set. The model size was as follows: $200 \mathrm{~m} \times 50 \mathrm{~m} \times 28.02 \mathrm{~m}$, creep model is adopted to generate an anticline structure in the direction of the model strike, and in situ stress is applied. After the model operation is stable, Surfer 8.0 software is used to analyze the stress state of the anticline model, and the results are shown in Figure 5.

As can be seen from the figure, the axial part of the anticline produces high stress concentration due to the tensile effect, and the stress direction is vertically downward. The two wings of the anticline, due to the extrusion action, also produce higher stress (the magnitude of stress is lower than that of the axial part), and the direction of stress is vertical upward. Under the joint action of extrusion and tension, shear stress is generated on both sides of the anticline, resulting in poor stability. With the advance of the working face, instability and failure are easy to occur in this area. This well explains why there are two sides of anticline in the dynamic emergence area and provides a good theoretical basis and reference significance for the prevention and control of the dynamic emergence in the later stage of the mine.

\subsection{Analysis of Other Influencing Factors.}

(1) Mining depth: the occurrence of rock burst has a certain relationship with the depth of coal seam. The statistical analysis shows that, in the same mining area or the same coal mine, the greater the mining depth, the greater the possibility of rock burst. According to the data from Poland, rock burst generally does not occur when the depth $H \leq 350 \mathrm{~m}$, and the danger gradually increases to a certain extent when the depth is 350 . The impact index $(\mathrm{Wt}=0.57)$ is 14 times higher than that at the mining depth of $500 \mathrm{~m}(\mathrm{Wt}=0.04)$. When the mining depth is extremely large, such as $1200-1500 \mathrm{~m}$, the impact index growth gradient will decrease, but its value will be extremely high. Buried depth is one of the influence factors of rock bursts occurring, due to the different geological and mining technical conditions of mining area, and the minimum critical depth of rock bursts occurring in different N2105 working face is more than our coal mining depth of working face. The largest coal seam buried depth increases gradually from southeast to northwest into the wind 


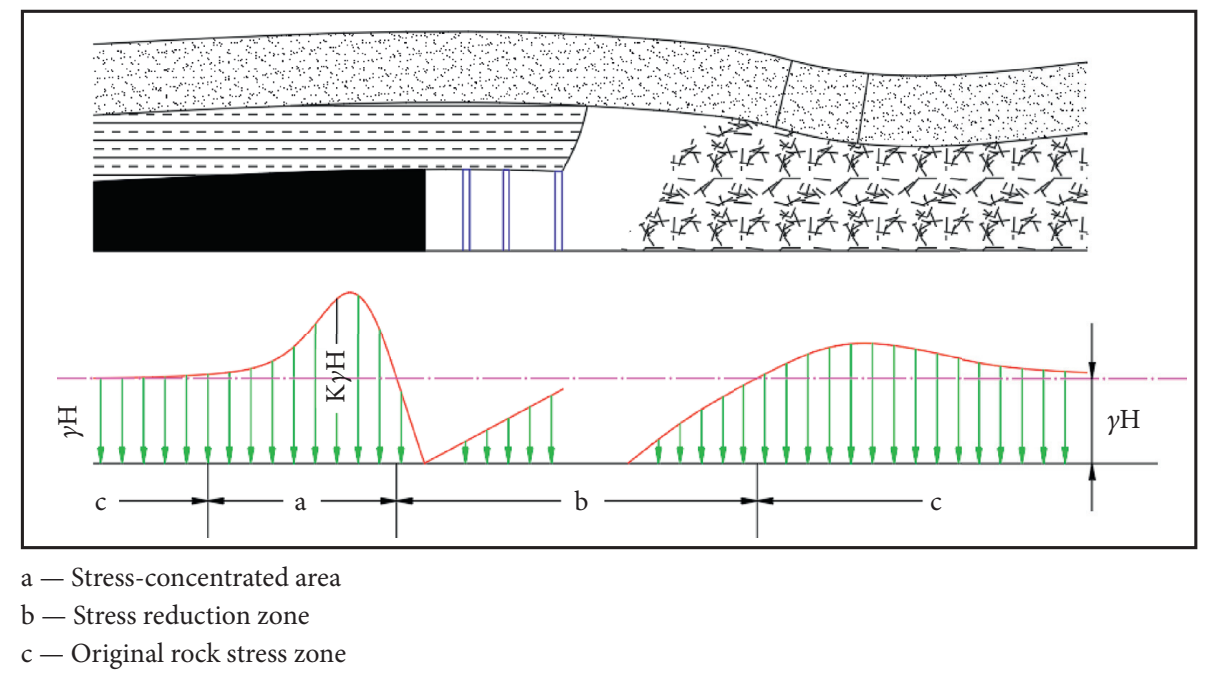

Figure 3: Distribution of bearing stress before and after the working face.

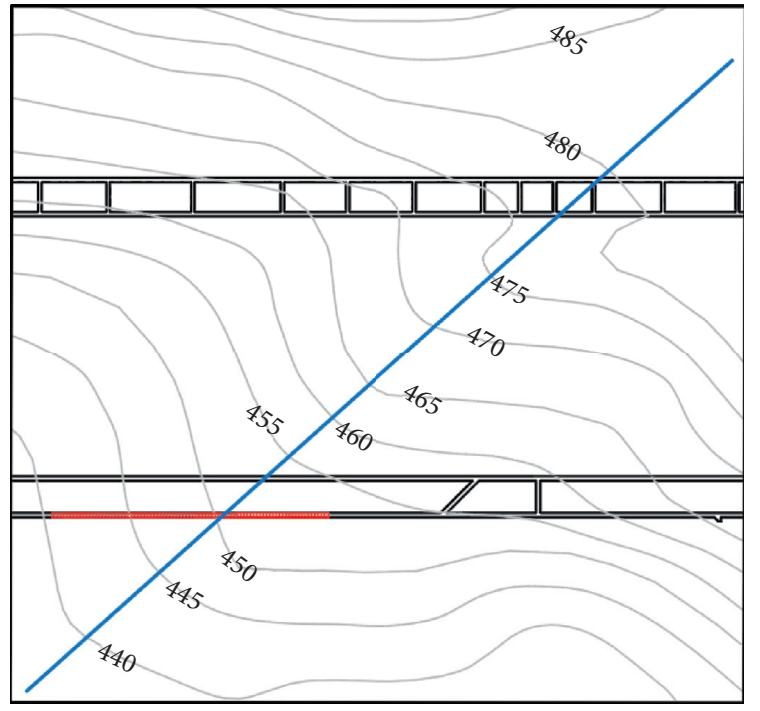

Figure 4: The anticlinal structure distribution of N2105 working face.

along the groove depth, and the whole is greater than the return air along the trough. Two dynamic events show that the critical depth of rock burst in Yuwu Coal Industry is about $600 \mathrm{~m}$.

(2) The coal pillar width: the loading effect of goaf roof activity on coal seam is the fundamental reason for the formation of rock burst pressure source; otherwise, the stress concentration caused by roadway excavation alone cannot promote the start of rock burst. The width of coal pillar has an important effect on the amount and concentration of elastic energy accumulation. The field measurement shows that the stress and elastoplastic distribution of $35 \mathrm{~m}$ wide coal pillar change dramatically after the stoping of N2105 working face. The width of elastic energy accumulation zone decreases sharply from about $29 \mathrm{~m}$ to about $14 \mathrm{~m}$ and gradually moves to the side far away from the goaf. The energy accumulation level continues to increase under the clamping action of coal body and support in the plastic zone on both sides. Thus, sufficient concentrated static load is provided for the occurrence of rock burst. Under the superposition of dynamic load caused by the continuous activity of overburden, it is easy to exceed the minimum energy of impact starting. If narrow coal pillars are left, all narrow coal pillars enter a plastic state in the process of roof subsidence and cannot accumulate sufficient elastic energy for impact starting. If a wider coal pillar is left, the incremental distribution of elastic energy of coal body caused by roof subsidence is more uniform, which can avoid the problem of excessive concentration of local accumulation and then reduce the risk of impact.

(3) Gas effect: with the increase of mine mining depth, rock burst and outburst often coexist in high gas seam. There is a wide coal pillar with high gas on one side of $\mathrm{N} 2105$ working face. In the process of working face mining, the deformation and failure process of coal and rock is not only affected by in situ stress, but also inevitably affected by gas pressure. In the process of mining, when the stress on one side of the wide coal pillar exceeds the maximum stress it can withstand, the coal body is deformed and damaged, thus improving the original permeability, causing a large amount of gas to gush out and gather in some areas, and there are outstanding hidden dangers. According to the actual situation, when the first floor heave occurs, the $35 \mathrm{~m}$ wide coal pillar between the "air inlet passage and belt passage" has been formed for nearly $1 \mathrm{~A}$ years, and the gas in the coal pillar and the surrounding rock of retaining roadway gradually escapes through the shallow cracks in the surrounding rock of the roadway, and the gas content is relatively low. According to the monitoring of the gas concentration near the sump before and after the occurrence of the two floor 


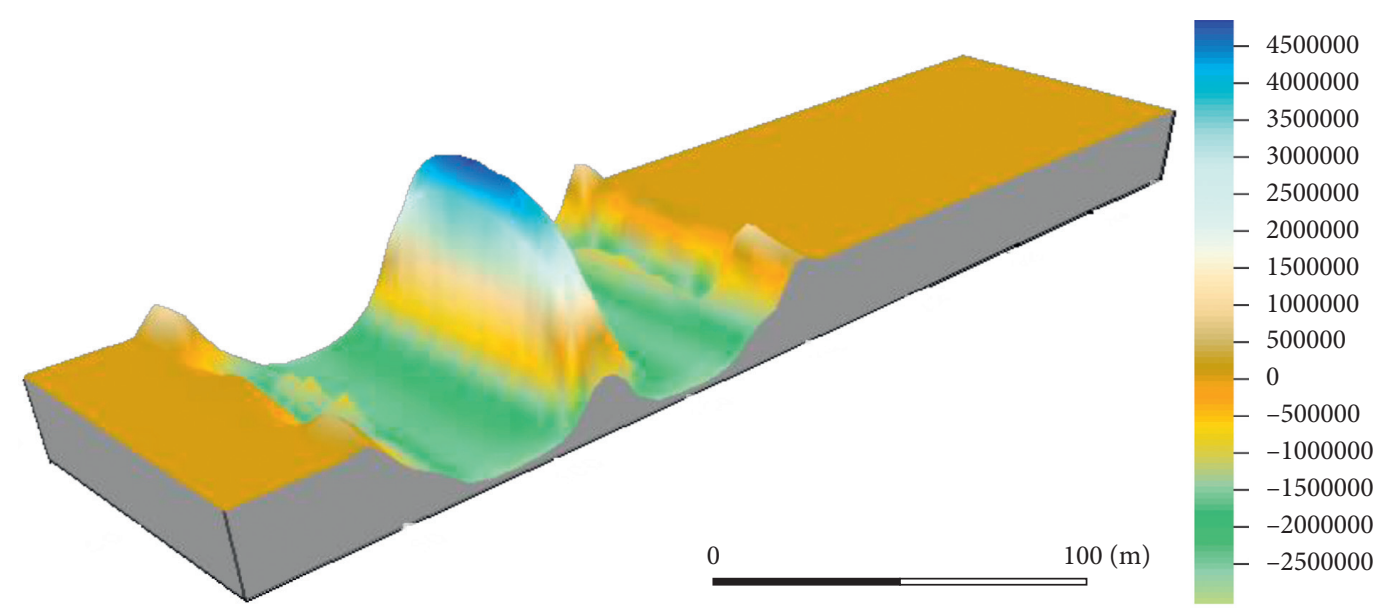

Figure 5: Force analysis of anticline.

heaves, the change curve of the gas concentration at the sump before and after the two floor heave is shown in Figure 6.

According to Figure 6, at the moment of the first floor heaving, there was a local gas outburst, and the gas concentration near the water silo rose rapidly to $1.34 \%$, and the coal pillar and surrounding rock with roadway retaining showed a wider range of damage, and then the gas content gradually decreased. The situation of the second floor heave was similar, but the maximum gas concentration was reduced to $0.96 \%$. The above indicates that, with the deformation and failure of coal and rock, the gas concentration presents a decreasing trend. The gas pressure value of coal pillar before and after two floor heave events is measured. According to the measured data, the gas pressure of one side of coal seam decreases after the first dynamic appearance. From the perspective of energy consumption, with the decrease of gas pressure, the elastic energy and dissipated energy of coal seam will increase, which will enhance the bursting liability of coal seam and promote the composite dynamic disaster of coal and rock.

\section{Stress/Microseismic Monitoring and Analysis of Results}

3.1. Stress Monitoring and Dynamic Characteristics. According to the positions of the two dynamic manifestations in the N2105 working face of Yuwu Coal Industry, it can be judged that the dynamic manifestations of the inlet duct and the belt duct are more obvious. In order to obtain the stress evolution law of lateral coal body in the mining process of N2105 working face, three groups of borehole stress gauges were arranged in advance of the working face. The stress meter can sense the change of the vertical stress of the media and monitor the stability of surrounding rock. Among them, there are 12 sets of KSE-II drilling stress gauges with initial pressure of about $4 \mathrm{MPa}$, which can monitor the change of vertical stress of coal seam within the lateral range of $56 \mathrm{~m}$ in the goaf online. Each stress gauge in the group has different distances to the goaf, and the specific installation layout is shown in Figure 7.

Among them, No. $1 \sim$ No. 7 stress gauges are installed by drilling holes in the construction direction in the connecting roadway, and the hole depth is $10 \mathrm{~m}$. No. 8-12 stress gauges are installed through construction inclination drilling in the inlet roadway, and the strike spacing of measuring points is no more than $1.5 \mathrm{~m}$. Because the installation and power supply time of the stress meter are different, the monitoring time of each measuring point is not completely consistent. The effective detection data of each measuring point from March to September 2014 were extracted for analysis, and the stress variation law of the measuring point in different regions was significantly different. According to different change trends of stress, it can be divided into 5 intervals from A to E along the coal seam tendency, and stress changes at measuring points in each interval are shown in Figure 8.

According to Figure 8, the following can be concluded:

(1) For measuring points No. 1 No. 4, the stress of measuring points generally increases when the working face is near and begins to decrease when the working face is nearby. The closer the measuring point is to the goaf, the earlier the descent time begins. Mechanism analysis: the mining leads to the roof lead and lateral subsidence of the working face, resulting in the increase of stress. When the subsidence is too large, plastic failure occurs in a certain range of coal seam, and the stress decreases. The lateral failure expands from the outside to the inside. The closer the distance to the goaf, the earlier the plastic failure time, and the earlier the stress decrease time.

(2) For measuring points No. 5 and No. 6, the stress starts to rise when it is ahead of the working face. In general, the closer to the goaf, the greater the increase of measuring points. When the working face is $70 \mathrm{~m}$ behind, the stress growth rate increases. When the working face is $300 \mathrm{~m}$ behind, the stress tends to be stable. Mechanism analysis: the roof fracture rotation of goaf has periodic characteristics, which 


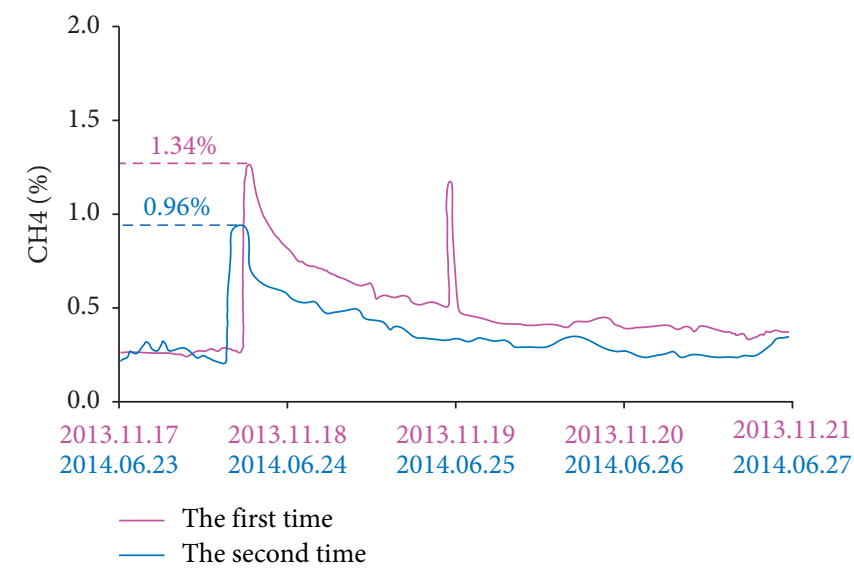

FIgURE 6: Change curve of gas concentration around sump before and after two floor heave.

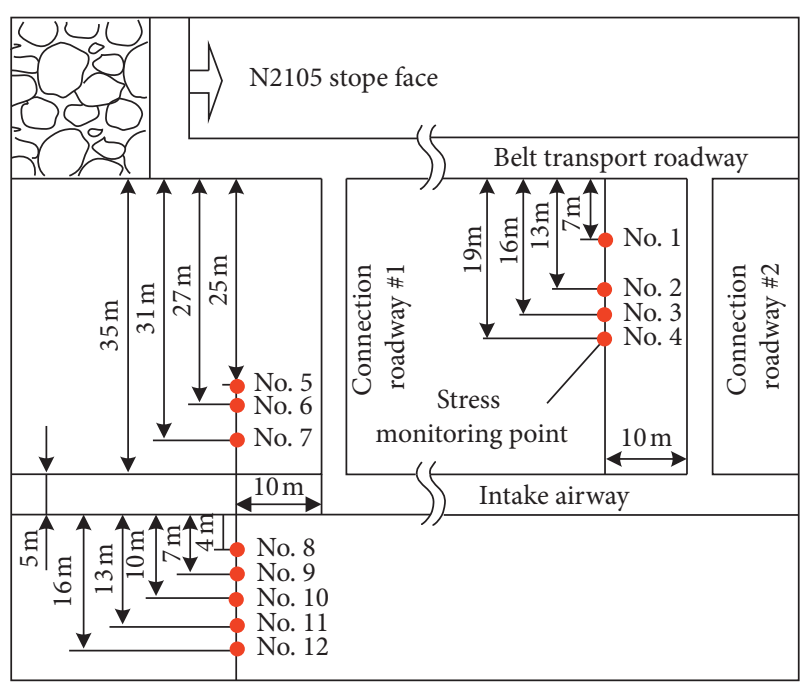

Figure 7: Installation plan of stress monitoring system.

determines the periodic characteristics of stress change in the lower coal seam. The roof activity time is long, and it tends to be stable after $300 \mathrm{~m}$ lag of the working face.

(3) For measuring point No. 7, the stress starts to increase when it is ahead of the working face. When the working face is $70 \mathrm{~m}$ behind, the stress tends to be stable. When the working face is $170 \mathrm{~m}$ behind, the stress begins to decrease. Mechanism analysis: No. 7 measuring point penetrates $4 \mathrm{~m}$ into the roadway wall. Under the action of the lateral abutment pressure of the roadway and the continuously increasing lateral abutment pressure of the goaf, plastic failure occurs, and stress decreases. That is, the width of the plastic zone on the inner side of the roadway is enlarged to a depth of $4 \mathrm{~m}$.

(4) For measuring point No. 8, similar to measuring point No. 7, the measuring point is $4 \mathrm{~m}$ deep into the roadway wall, but it is farther away from the goaf and is relatively less affected by the superposition of lateral abutment pressure in the goaf, so the time of plastic failure (stress reduction) is later. At the same time, it shows that the width of plastic zone is about $4 \mathrm{~m}$.

(5) For 9-12 points, like 5 and 6 points, lag of working face $300 \mathrm{~m}$, stress tends to be stable, and the difference is 9-12 maximum stress monitoring the whole less than the maximum stress monitoring points 5 and 6 . This is associated with goaf distance, affected by the goaf and wide coal pillars; the closer the goaf distance stability, the greater the stress monitoring value.

Based on the above measured data and result analysis, the influence of goaf formation on wide coal pillar and roadway retention in N2105 working face can be divided into four stages, and the elastoplastic transformation and stress evolution characteristics of coal body corresponding to each stage are shown in Figure 9.

Stage 1: outside the range of $60 \mathrm{~m}$ in front of the working face before the impact of mining, the side part is the lateral abutment pressure of the roadway, and the depth of plastic zone is about $3 \mathrm{~m}$. The stress distribution is stable due to the influence of roadway excavation itself.

Stage 2: during the advance influence of the working face, the working face is within $50 \mathrm{~m}$ to the front. With the superposition of the advance and lateral abutment pressure in the working face, the stress on the coal pillar increases as a whole, and the increase is more large at the side near the goaf.

Stage 3: during the goaf roof activity, the working face shall be within $300 \mathrm{~m}$ to the rear. (1) The stress inside the coal pillar (within a range of about $16 \mathrm{~m}$ away from the goaf) can exceed the yield limit within $14 \mathrm{~m}$ after the working face is pushed, and the stress drop occurs. (2) The lateral stress of coal pillar continues to increase, and the growth rate accelerates when the lag time is $70 \mathrm{~m}$, and the growth rate slows down when the lag time is $200 \mathrm{~m}$ and then becomes stable until the lag time is $300 \mathrm{~m}$. (3) The stress outside the entry continues to increase until $300 \mathrm{~m}$ behind the working face. The 


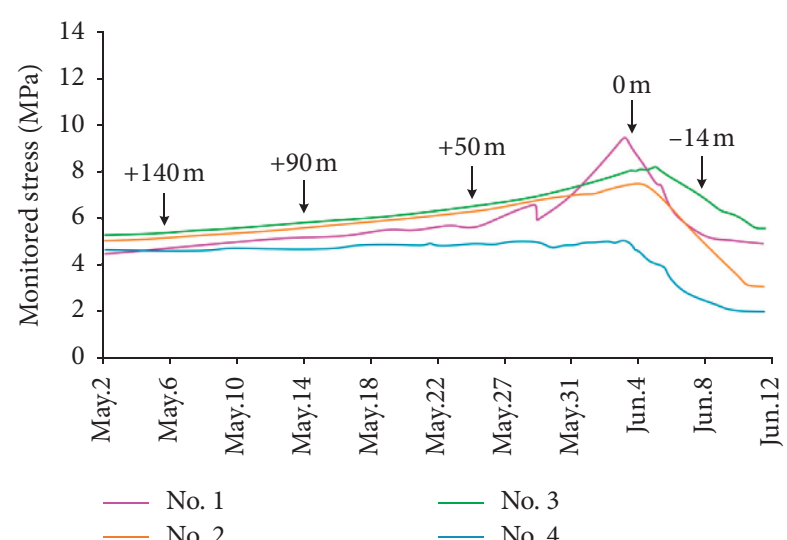

(a)

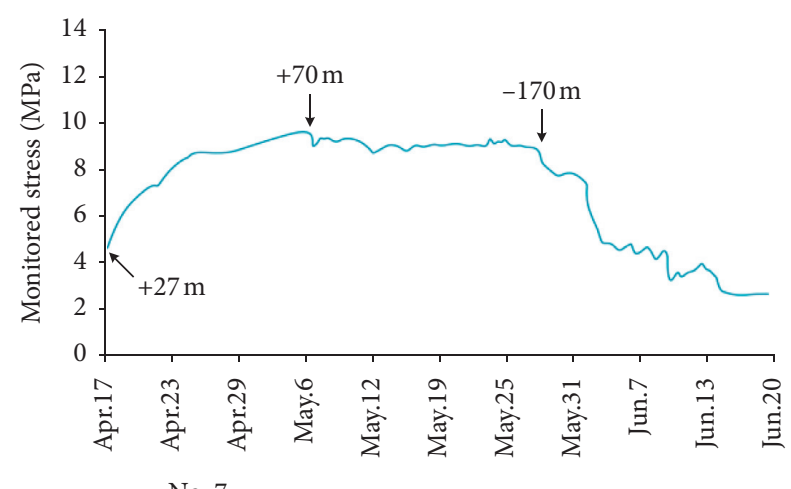

(c)

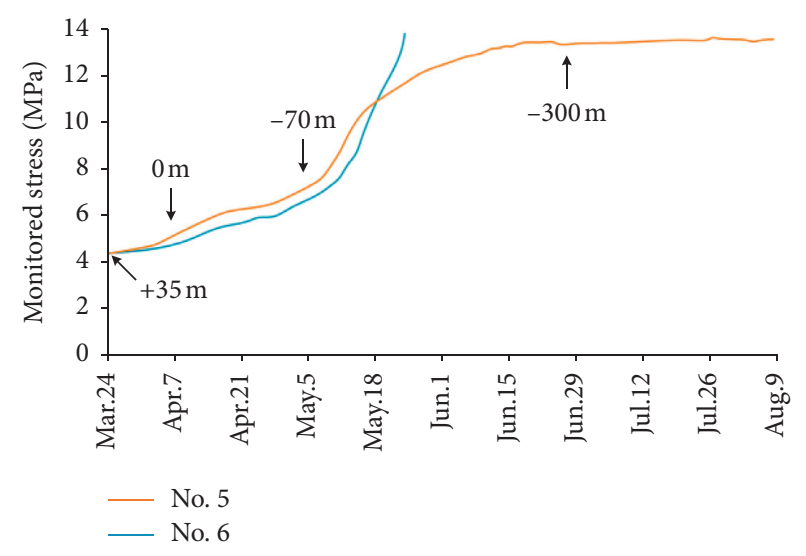

(b)

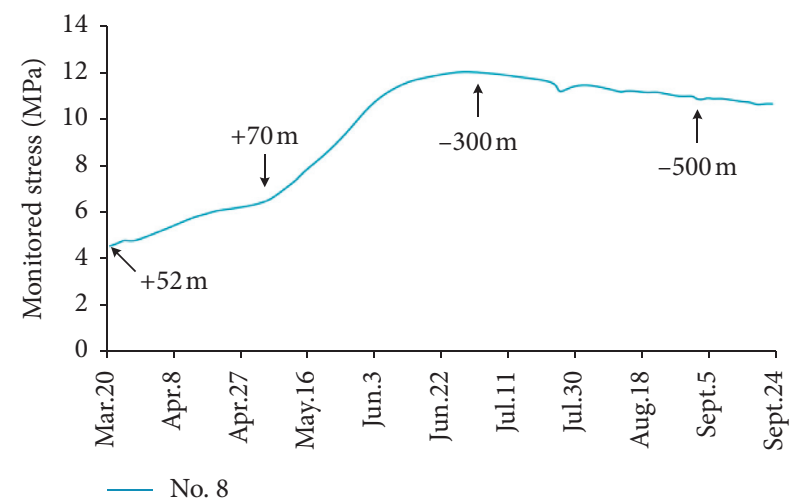

(d)

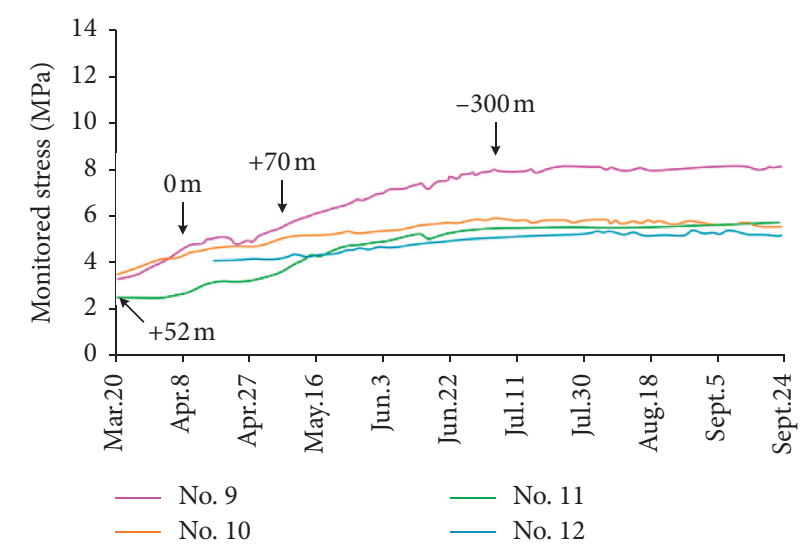

(e)

FIGURE 8: Stress monitoring curve of measuring points in A E interval. Note. $+140 \mathrm{~m}$ means that the measuring point is located $140 \mathrm{~m}$ ahead of the working face; $-14 \mathrm{~m}$ means that the measuring point is located $14 \mathrm{~m}$ behind the working face.

closer it is to the goaf, the greater the increase is, and the stress increase is not obvious beyond $7 \mathrm{~m}$ of the roadway wall. (4) The plastic zone of the coal pillar side with the roadway remaining is slightly enlarged, with width from $3 \mathrm{~m}$ to $4-5 \mathrm{~m}$, and the width of the plastic zone of the outer side is basically unchanged.

Stage 4: after the goaf roof is stabilized, it is $300 \mathrm{~m}$ behind the working face. The stress of the surrounding rock is basically stable.
According to the abovementioned monitoring data analysis, in order to display the elastoplastic transformation and stress evolution process characteristics of coal body from different perspectives, the variation of lateral abutment pressure distribution in goaf at different stages and its corresponding relationship with the expansion of plastic zone are drawn in the form of dipping profile, as shown in Figure 10. It can be seen that the force of lateral coal seam has undergone a complex evolution process after mining; 


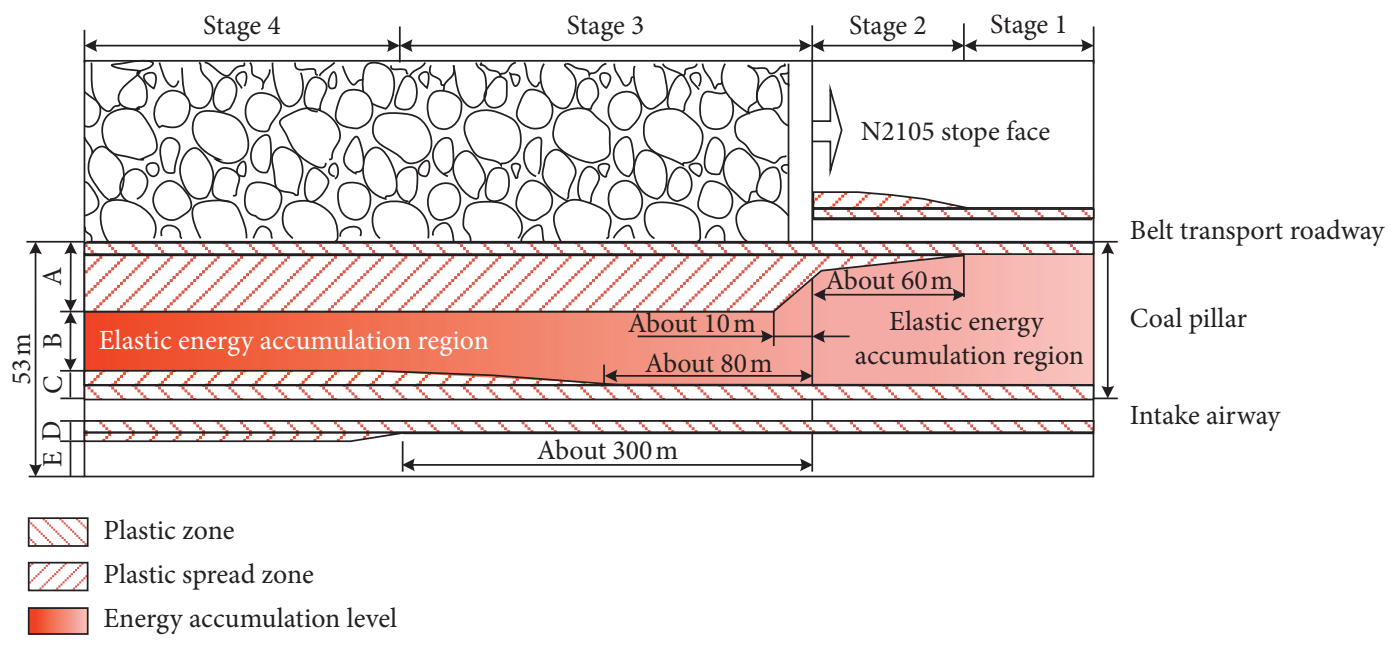

Figure 9: Characteristics of "strike" stage of elastoplastic transformation and stress evolution of coal body.

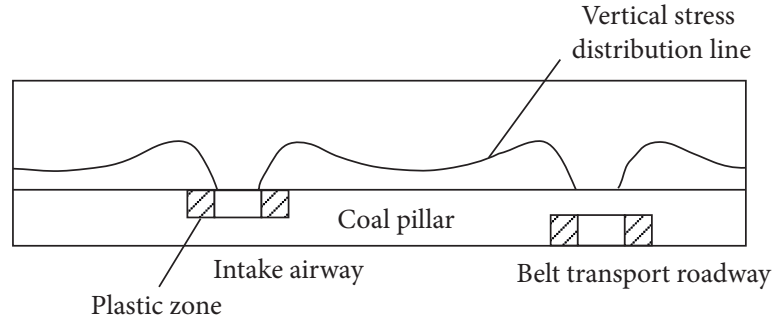

(a)

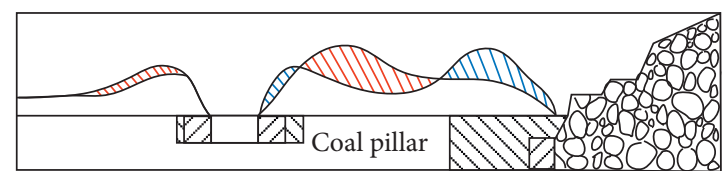

Belt transport roadway (goaf)

(c)

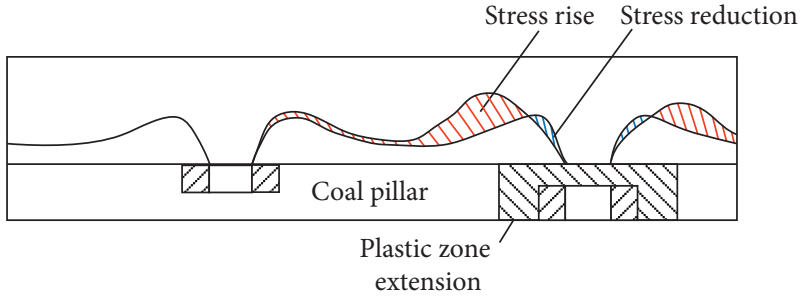

(b)

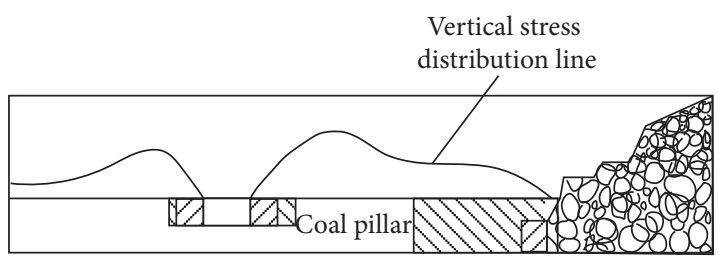

(d)

FIGURE 10: Characteristics of elastoplastic transformation and stress evolution "dip" stage of coal.

especially the vertical stress of coal pillar shows the distribution law of "the same height inside and outside; the inner high and the outer bottom; the inner low and the outer high" successively.

In conclusion, in the process of mining, the period when the goaf has the most severe influence on the wide coal pillar and the roadway retention is within $300 \mathrm{~m}$ behind the working face. In this stage, with the extension of time, the stress and elastic-plastic zone distribution of the wide coal pillar are sharply adjusted, the width of the elastic zone is continuously reduced, and the elastic energy migrates and concentrates on the roadway retention side. The deformation and failure degree of the roadway side facing the goaf gradually exceeds that of the roadway side.

3.2. Microseismic Monitoring and Microseismic Distribution. Coal and rock mass underground is a kind of stress medium. When they are deformed and destroyed under stress, it will be accompanied by the release of energy, and microseismic is one of the physical effects of this release process, that is, the vibration effect caused by the release of deformation energy in the form of vibration wave with a lower frequency $(f<100 \mathrm{~Hz})$ during the process of stress and failure. Through simulation calculation, the expected value of the positioning error is obtained. After comparative analysis, the optimal layout scheme for the establishment of the microseismic network is obtained: decorate a total of eight SPI-70 microseismic monitoring probes, respectively, arranged on $\mathrm{N} 2105$ face into the wind along the groove and roadway roof tile platoon lane, lane, and the roadway floor, and concrete installation layout is shown in Figure 11, figure in January 23, 2014, mining face on the left position, the right to stop line, ND the red line mark position appeared for two power positions. The blue circles indicate microseismic monitoring sites.

The microseismic monitoring system was officially put into operation on March 26, 2014. Figure 12 shows the plane 


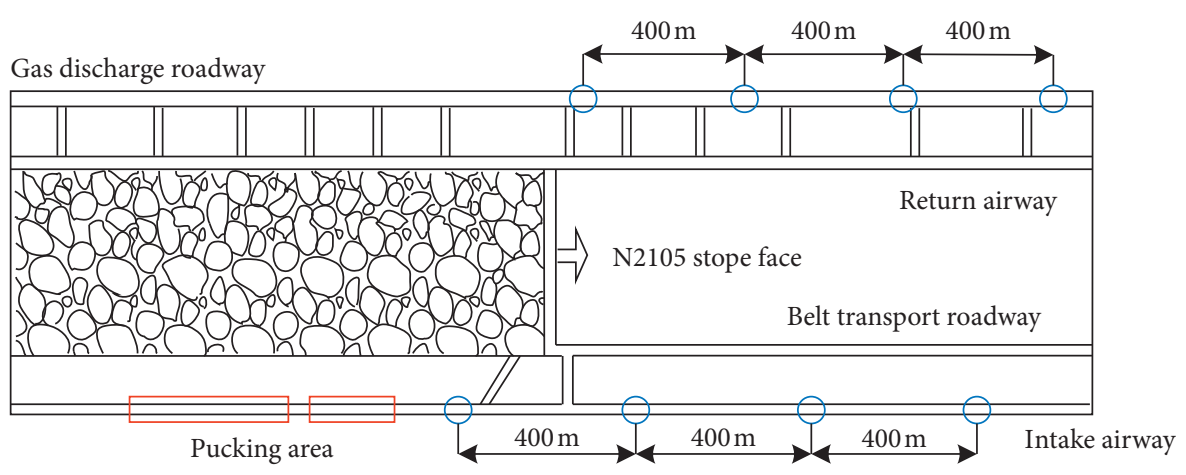

FIgURE 11: Installation plan of microseismic system.

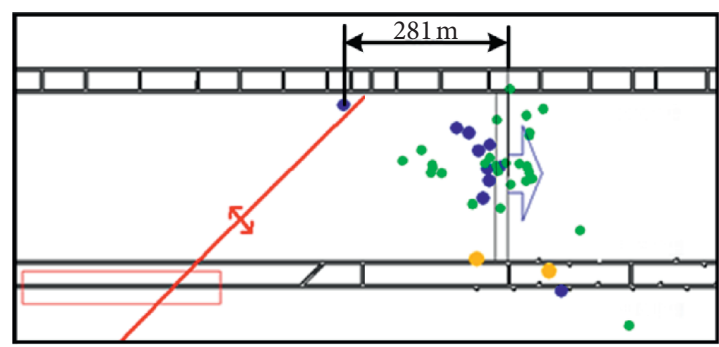

(a)

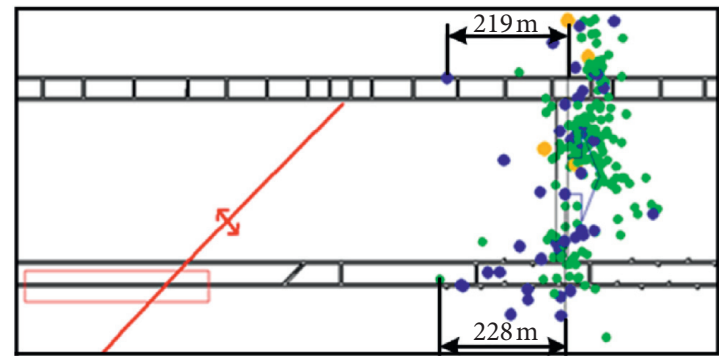

(c)

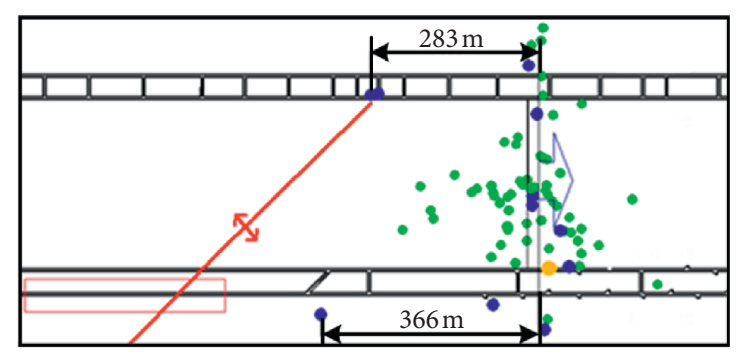

(b)

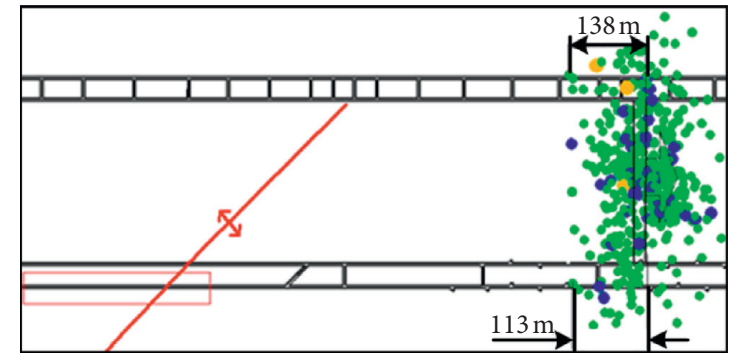

(d)

FIgURE 12: Projection of microseismic events at N2105 working face.

projection of microseismic events at working face N2105 during the period of March 26, 2014, solstice and June 8, 2014. The working face is projected once for every $60 \mathrm{~m}$ advance. In the figure, the position marked by the red line frame is the position of two dynamic manifestations, and the position marked by the red line is the axis of the anticline. The larger the diameter of the solid circle is, the greater the energy is. The energy of the green circle is less than $100 \mathrm{~J}$, the energy of the blue circle is between 100 and $1000 \mathrm{~J}$, and the energy of the yellow circle is more than $1000 \mathrm{~J}$. Figure 13 shows the relationship between microseismic frequency in different areas and the relative position of the working face.

According to Figures 12 and 13, the following can be concluded:

(1) Microseismic events are mainly distributed in the coal strata at the edge of the goaf, and there are few microseismic events in the middle of the goaf, and the overall distribution presents an inverse " $C$ " type.
(2) The distance between the microseismic in the middle of the working face and the working face is the largest, and the leading distance becomes smaller as it approaches the roadway on both sides.

(3) The number of microseismic events in front of the working face is much greater than that behind the working face, and the frequency of microseismic events behind the working face is generally negatively correlated with the distance behind the working face.

(4) The active microseismic area in the middle of the working face is located $50 \mathrm{~m}$ in front of the working face, and the microseismic activity continues to $30-50 \mathrm{~m}$ behind the working face. The active microseismic area at the side of the roadway was located $30 \mathrm{~m}$ in front of the working face, and the microseismic activity continued to $100-180 \mathrm{~m}$ behind the working face. 


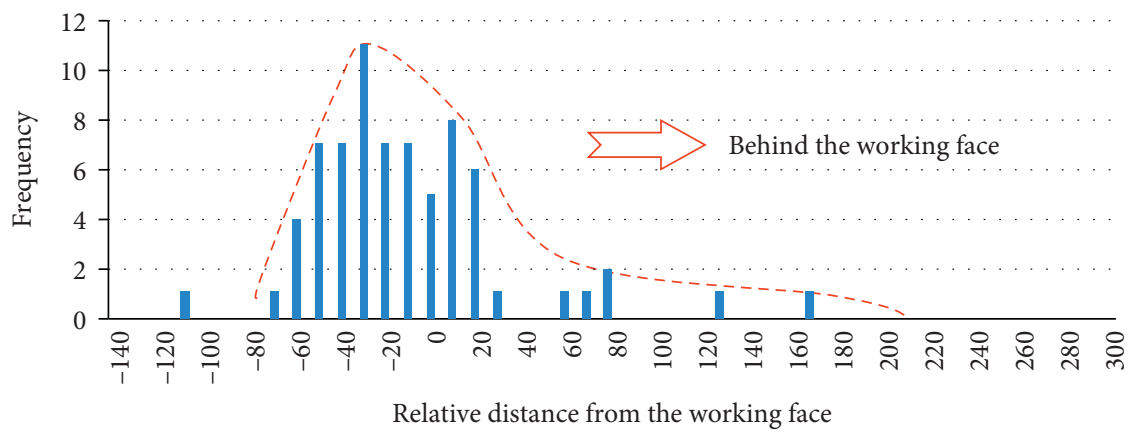

(a)

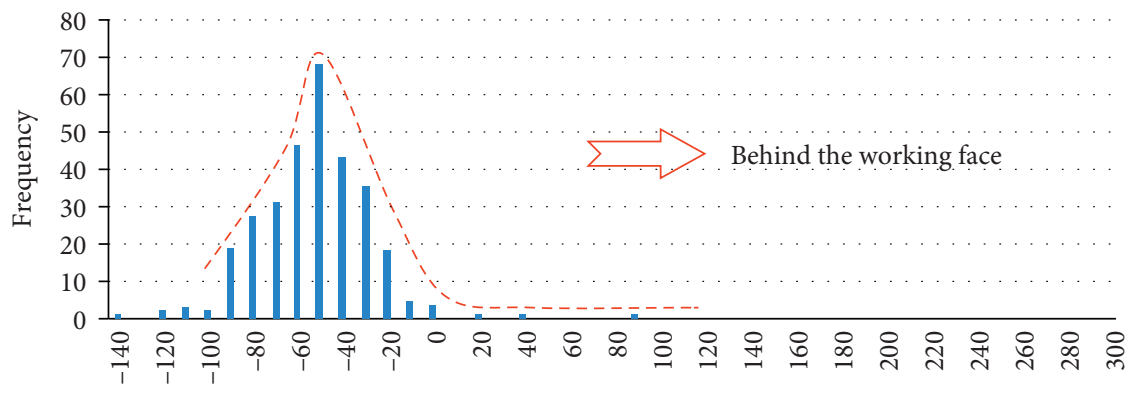

Relative distance from the working face

(b)

FIGURE 13: Frequency statistics of microseismic events.

To sum up, in the process of coal rock composite dynamic disaster prevention and control, it is necessary to focus on the $50 \mathrm{~m}$ area around the middle of the working face and the corresponding dangerous areas at the roadway side. Prevention and control measures such as forced caving, coal pillar pressure relief, and coal seam strength reduction can be taken to avoid large dynamic phenomena in the dangerous areas. At the same time, continuous monitoring should be carried out in key areas, so that preventive measures can be taken in advance.

\section{Discussion}

4.1. Analysis of Impact of Gas Action on Bursting Liability of Coal Seam in Wide Coal Pillar Roadway. With the coal resources into the deep mining, the dynamic disasters occurring in the process of coal mining gradually show the characteristics of rock burst and coal and gas outburst. It is generally believed that both rock burst and outburst are the result of the violent release of the high elastic potential accumulated in the coal and rock mass when the mechanical system composed of coal and rock mass is unstable. However, in the process of rock burst, the in situ stress plays a decisive role, while, in the process of rock burst, the highpressure gas plays a decisive role, and the in situ stress plays an excitation role. Therefore, the researchers believe that the burst is the burst with gas effect, while the burst is the burst without or without gas effect, emphasizing that the difference between the two lies in the different degree of gas participation. Of course, the occurrence of dynamic disasters not only depends on the degree of gas participation, but also is affected by multiple factors such as coal seam hardness, mining depth, and geological structure. The deformation and failure process of coal body is not only affected by in situ stress, but also affected by gas pressure when there is dynamic appearance of high gas pillar in impact type coal seam. It is not accurate to treat it purely as an outburst (rock burst with gas). In general, at present, the study of rock burst in deep coal seam is still on the theoretical basis of ignoring or without the participation of gas, and the study of rock burst liability under the action of gas is the lack of indepth understanding. Previously, some scholars conducted experimental analysis from the mechanical properties of coal and rock, acoustic emission characteristics, and energy dissipation and obtained the experimental conclusion that the increase of gas pressure will weaken the bursting liability of coal samples [24, 25].

According to the two dynamic events of N2105 working face in Yuwu Coal Industry, the gas concentration at the water silo before and after the occurrence of two floor heave and the gas pressure in the coal body were compared. With the deformation and failure of coal rock, the gas concentration showed a decreasing trend, and the gas pressure also showed a decrease in pressure relief. The concrete example shows that, with the decrease of gas pressure and content, the elastic energy and dissipated energy of coal seam will increase, but the bursting liability of coal seam will be enhanced, and the composite dynamic disaster of coal and rock will be promoted. According to the test results and specific cases, when there is a wide coal pillar with high gas content on one side in the process of mining, when the stress of the coal body exceeds the maximum stress it can bear, there are 


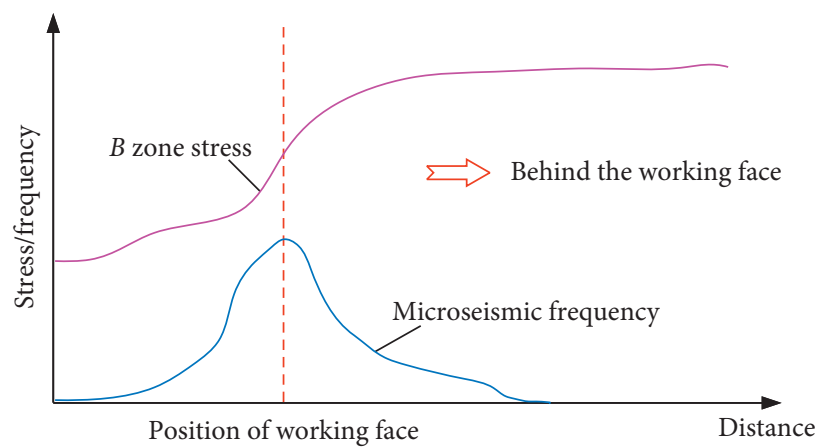

Figure 14: Distribution of stress and microseismic in the lateral coal-series strata along the strike.

risks of deformation and failure, increased air permeability, and gas accumulation of the coal body. In the case of deep hard coal mining, it undoubtedly provides the necessary conditions for the coupling of rock burst and gas outburst. It is of guiding significance to systematically understand the coal rock composite dynamic disaster, especially the coal seam rock burst disaster with gas effect.

\subsection{Correlation Analysis of Wide Coal Pillar Stress Evolution} and Microseismic Distribution in Mining Process. According to the stress monitoring and microseismic monitoring data, the vertical stress of lateral coal seam in the process of mining face and the distribution law of microseismic distribution along the strike can be obtained, as shown in Figure 14.

According to Figure 14, the active area of microseismic was concentrated near the working face, and the microseismic events behind the goaf decreased sharply. The stress of lateral coal seam increases gradually as it is far away from the working face, and the maximum stress in elastic zone (B zone) of coal pillar appears beyond $300 \mathrm{~m}$ behind the working face. There is a great difference between the active law of lateral microseismic in goaf and the overall trend of vertical stress change in coal seam. However, it is worth noting that the inflection point at which the stress in the elastic area of coal pillar increases sharply (shown in the figure as the position with the maximum slope) corresponds to the active microseismic section, that is, the position of the mining face. On the one hand, it reflects the difference between the characteristics of stress evolution and the distribution law of microseismic. On the other hand, it also verifies the unity of stress monitoring and microseismic monitoring from the side, because the sharp change of coal pillar stress promotes the occurrence of microseismic activities; that is, there is a correlation between the dynamic characteristics of the mining process of roadway with high gas and wide coal pillar and the distribution law of microseismic.

\section{Conclusion}

(1) Combined with the two dynamic events of N2105 working face in Yuwu Coal Industry, the causes are analyzed from the perspective of structural mechanics and geomechanics. According to the rock beam theory, it is judged that the roof structure of N2105 working face belongs to the structure type of "cantilever beam." When the stoping distance increases to a certain extent, the suspended roof distance is large enough. The lack of lateral stress in the back roof of the goaf is easy to cause unbalanced fracture, which produces a large impact pressure for the reserved protective coal pillar behind the goaf, causing the bulge of the coal seam floor. According to the analysis of geological structure, it is considered that the interaction between the combined stress generated by the anticlinal structure under the working face and the abutment pressure under the working face will produce superposition effect, which promotes the occurrence of dynamic appearance.

(2) According to the complexity of complex dynamic disasters in deep mining and the specific conditions of the mine, the influence of mining depth, coal pillar width, and gas action on dynamic development is analyzed. The critical depth of rock burst in Yuwu coal industry is about $600 \mathrm{~m}$. The increase of elastic energy of coal body caused by roof subsidence is distributed more evenly with the increase of coal pillar width, which can avoid the problem of excessive concentration of local accumulation. With the decrease of gas pressure in coal seam, the elastic energy and dissipated energy of coal seam increase, but the bursting liability of coal seam is enhanced, which promotes the composite dynamic disaster of coal and rock.

(3) According to the monitoring data and analysis, the coal seam is divided into 5 sections along the coal seam tendency and 4 stages along the coal seam strike, and the stress evolution characteristics of each section and stage are obtained. Generally speaking, the vertical stress of coal seam in the lateral range of $53 \mathrm{~m}$ of the working face is adjusted to different degrees and tends to be stable until $300 \mathrm{~m}$ behind the working face.

(4) Microseismic monitoring was carried out on the coal seam at one side of the working face. The plane projection map of microseismic events of N2105 working face during March 26, 2014, and June 8, 
2014, was obtained, and the microseismic frequency was calculated. The microseismic activity in the middle of the working face was located $50 \mathrm{~m}$ in front of the working face, and the microseismic activity continued to $30-50 \mathrm{~m}$ behind the working face. The active microseismic area at the side of the roadway was located $30 \mathrm{~m}$ in front of the working face, and the microseismic activity continued to $100-180 \mathrm{~m}$ behind the working face.

(5) Elastic area coal pillar stress occurs sharply rising inflection point corresponding to the seismic active extents and shows gas wide roadway coal pillar stoping process dynamic characteristics and seismic distribution correlation, and dramatic change due to the stress of the coal pillar has promoted the happening of the microseismic activity, from the side, to verify the stress monitoring and the unity of microseismic monitoring.

\section{Data Availability}

The data used to support the findings of this study are available from the corresponding author upon request.

\section{Conflicts of Interest}

The authors declare no conflicts of interest.

\section{Acknowledgments}

The authors would like to express their gratitude to engineers from Yuwu Coal Industry and Mining Research Institute of Tiandi Technology Co., Ltd., for their help in the field tests. The authors thank the State Key Laboratory Cultivation Base for Gas Geology and Gas Control. This study was supported by the NSFC-Shanxi Coal-based LowCarbon Joint Fund Key Project (grant no. U1810203), The Development Plan of Young Backbone Teachers in Colleges and Universities of Henan Province (grant nos. 2016GGJS042), Joint Talent Fund of NSFC-The People's Government of Henan Province (grant no. U1304502), and Key R\&D and Promotion Projects in Henan Province (grant no. 212102310013).

\section{References}

[1] T. Li, M. F. Cai, J. A. Wang et al., "Discussion on relativity between rockburst and gas in deep exploitation," Journal of China Coal Society, vol. 30, no. 5, pp. 562-567, 2005.

[2] L. Yuan, Y. D. Jiang, X. Q. He et al., "Research progress of precise risk accurate identification and monitoring early warning on typical dynamic disasters in coal mine," Journal of China Coal Society, vol. 43, no. 2, pp. 306-318, 2018.

[3] Q. X. Qi, Y. S. Pan, L. Y. Shu et al., "Theory and technical framework of prevention and control with different sources in multi-scales for coal and rock dynamic disasters in deep mining of coal mines," Journal of China Coal Society, vol. 43, no. 7, pp. 1801-1810, 2018.

[4] K. Wang and F. Du, "Coal-gas compound dynamic disasters in China: a review," Process Safety and Environmental Protection, vol. 133, pp. 1-17, 2020.
[5] J. F. Pan, Q. X. Qi, S. H. Liu et al., "Characteristics, types and prevention and control technology of rockburst in deep coal mining in China," Journal of China Coal Society, vol. 45, no. 1, pp. 111-121, 2020.

[6] B. B. Gao, X. F. Mi, and R. L. Zhang, "Research status and prospect of compound dynamic disaster of deep mining in coal mine," Safety in Coal Mines, vol. 44, no. 11, pp. 175-178, 2013.

[7] Y.S. Pan, "Integrated study on compound dynamic disaster of coal-gas outburst and rockburst," Journal of China Coal Society, vol. 41, no. 1, pp. 105-112, 2016.

[8] N. I. Aziz and W. Ming-li, "The effect of sorbed gas on the strength of coal-an experimental study," Geotechnical \& Geological Engineering, vol. 17, pp. 387-402, 1999.

[9] K. Ogieglo, M. Lubryka, J. Kutkowski et al., "Influence of mine vibration on gas emission in working face," Journal of Mining \& Safety Engineering, vol. 22, no. 2, pp. 109-111, 2005.

[10] Y. D. Jiang, Y. S. Pan, F. X. Jiang et al., "State of the art review on mechanism and prevention of coal bumps in China," Journal of China Coal Society, vol. 39, no. 2, pp. 205-213, 2014.

[11] M. T. Zhang, Z. H. Xu, Y. S. Pan et al., "A united insta-bilty theory on coal (rock) burst and outburst," Journal of China Coal Society, vol. 16, no. 4, pp. 48-53, 1991.

[12] X. S. He, S. Y. Li, K. Pan et al., "Mining seismicity, gas outburst and the sig-nificance of their relationship in the study of physics of earthquake source," (English edition) Acta Seismologica Sinica, vol. 20, no. 3, pp. 332-347, 2007.

[13] Z. Wang, G. Z. Yin, Q. T. Hu, and H.-W. Jin, "Inducing and transforming conditions from rockburst to coal-gas outburst in a high gassy coal seam," Journal of Mining \& Safety Engineering, vol. 27, no. 4, pp. 572-575, 2010.

[14] F. Du, K. Wang, G. D. Wang, Y. F. Jiang, C. P. Xin, and $\mathrm{X}$. Zhang, "Investigation of the acoustic emission characteristics during deformation and failure of gas-bearing coalrock combined bodies," Journal of Loss Prevention in the Process Industries, vol. 55, pp. 253-266, 2018.

[15] Y. M. Geng, "Mechanism of compound dynamic disaster and integrated prevention technology in deep mine," Safety In Coal Mines, vol. 47, no. 11, pp. 73-76, 2016.

[16] B. B. Gao, H. G. Li, H. M. Li, R. F. Yuan, and Y. P. Liu, "Current situation of the study on acoustic emission and microseism monitoring of coupling dynamic catastrophe for gas-filled coal-rock," Progress in Geophysics, vol. 29, no. 2, pp. 689-697, 2014.

[17] F. W. Zhang and T. Li, "Understanding of composite briquette and gas dynamic disaster in deep mining," China Energy and Environmental Protection, vol. 4, pp. 73-76, 2009.

[18] L. Y. Zhu, Z. H. Li, and H. Q. Li, "Consequential mechanism and the monitoring technique for the gassy coal-rock dynamics disaster in the deep mining," Journal of Safety and Environment, vol. 17, no. 3, pp. 937-942, 2017.

[19] G. Z. Yin, X. Li, J. Lu et al., "Disaster-causing mechanism of compound dynamic disaster in deep mining under static and dynamic load conditions," Journal of China Coal Society, vol. 42, no. 9, pp. 2316-2326, 2017.

[20] W. T. Cao, Z. Q. Yang, L. K. Zhang et al., "Mechanism and application of pressure relief with high-pressure water jet to prevent and control compound dynamic disaster," Journal of Safety Science and Technology, vol. 16, no. 2, pp. 18-23, 2020.

[21] Q. X. Qi, Y. S. Pan, H. T. Li et al., "Theoretical basis and key technology of prevention and control of coal-rock dynamic disasters in deep coal mining," Journal of China Coal Society, vol. 45, no. 5, pp. 1567-1584, 2020. 
[22] B. B. Gao, Y. N. Qian, L. W. Chen et al., "Study on gas pressure affected to bump potential of coal sample," Coal Science and Technology, vol. 46, no. 10, pp. 58-64, 2018.

[23] J. F. Ju, J. L. Xu, and W. B. Zhu, "Influence of key strata cantilever structure motion on end-face fall in fully-mechanized face with super great mining height," Journal of China Coal Society, vol. 39, no. 7, pp. 1197-1204, 2014.

[24] W. L. Yin, Y. S. Pan, Z. H. Li et al., "Condition and influence factor of rock burst in high gassy coal seam," Chinese Journal of Theoretical and Applied Mechanics, vol. 49, no. 3, pp. 716-725, 2017.

[25] B. B. Gao, Z. G. Wang, H. M. Li et al., "Experimental study on the effect of outburst - proneness of coal by gas pressure," Journal of China Coal Society, vol. 43, no. S1, pp. 140-148, 2020. 